\title{
АНТОЦИАНЫ ПЛОДОВ НЕКОТОРЫХ ВИДОВ БОЯРЫШНИКА (CRATAEGUS L., ROSACEAE)
}

\author{
() В.И. Дейнека ${ }^{l *}$, С.Л. Макаревич ${ }^{I}$, Л.А. Дейнека ${ }^{I}$, Г.А. Фирсов ${ }^{2}$, В.Н. Сорокопудов, М.Ю. Третьяков", \\ С.А. Бакшутов ${ }^{\text {I }}$
}

${ }^{1}$ Национальный исследовательский университет Белгородский государственный университет, ул. Победы, 85, Белгород, 308015 (Россия), e-mail:deineka@bsu.edu.ru

${ }^{2}$ Ботанический институт им. В.Л. Комарова РАН, ул. Професссора Попова, 2, Санкт-Петербург, 197376 (Россия), e-mail: gennady_firsov@mail.ru

В методом ВЭЖХ с диодно-матричным и масс-спектрометрическим детекторами исследован антоциановый комплекс плодов двух видов боярышника C. chlorosarca Maxim. и C. pentagyna Waldst. et Kit.. В плодах найдены цианидин-3-галактозид, цианидин-3-глюкозид, цианидин-3-арабинозид и цианидин-3-ксилозид. Суммарный уровень накопления антоцианов оказался наивысшим для плодов вида $C$. chlorosarca: 0,460-0,620 г на 100 г свежих плодов в пересчете на цианидин-3-глюкозида хлорид. Установлено, что по содержанию антоцианов и по антиоксидантной активности плоды $C$. chlorosarca сопоставимы с высушенными бутонами гибискуса суданского (каркаде) и могут быть использованы для приготовления напитков при небольшом подкислении.

Ключевые слова: антоцианы, Crataegus, плоды, антиоксидантная активность.

Исследование выполнено при финансовой поддержке Министерства образования и науки РФ, государственное задание вузу на 2013 г., проект №3.1785.2011.

\section{Ведение}

Антоцианы являются природными соединениями, обладающими в определенных условиях [1] окраской, вследствие чего они представляют интерес как колоранты для пищевой и медицинской промышленности. Антоцианы не только свободны от вредного действия на организм (поэтому должны вытеснить канцерогенные азокрасители из пищевой промышленности), но и, наоборот, - обладают высокой антиоксидантной активностью [2], способствующей проявлению ими многочисленных вариантов биологической активности - от противовоспалительной до антиканцерогенной [3]. Это объясняет интерес к растительным источникам антоцианов как для прямого употребления в пищу, так и для выделения из них колорантов для

Дейнека Виктор Иванович - профессор, доктор химических наук, e-mail: deineka@bsu.edu.ru Макаревич Сергей Леонидович - аспирант, e-mail: deineka@bsu.edu.ru

Дейнека Людмила Александровна - доцент, кандидат химических наук, e-mail: deineka@bsu.edu.ru

Фирсов Геннадий Афанасьевич - старший научный сотрудник, кандидат биологических наук, e-mail: gennady_firsov@mail.ru

Сорокопудов Владимир Николаевич - заместитель директора, доктор сельскохозяйственных наук, e-mail: sorokopudov@bsu.edu.ru

Бакшутов Сергей Александрович - аспирант, e-mail: baks922@rambler.ru пищевой и медицинской промышленности. Однако в различных растениях синтезируются различные виды антоцианов [6]; при этом известно, что антиоксидантная активность антоцианов зависит от их строения [7], поэтому видовой состав антоциановых комплексов должен иметь определенное значение при выборе исходного сырья для создания антиоксидантных композиций.

Обширный род боярышник (Crataegus L.) включают в подсемейство Maloideae Weber семейства розоцветные (Rosaceae Adans.). В это семейство входит 118 родов и примерно 3500 видов, главным образом из умеренных и субтропических областей земного шара [8]. К роду Crataegus относится около 1500 ви-

\footnotetext{
* Автор, с которым следует вести переписку.
} 
дов в умеренно теплых и субтропических областях Северного полушария, главным образом в Северной Америке [9]. Некоторые растения подсемейства яблоневые известны как хорошие источники накапливаемых в плодах антоцианов. К таким растениям прежде всего следует отнести аронию Мичурина (Aronia mitschurinii A. Skvorts. et Maitull.) - рекордсмена по уровню накопления антоцианов в плодах (свыше 800 мг/100 г свежих плодов). Этот же показатель довольно велик и у плодов разных видов ирги (Amelanchier sp.) - до 275 мг/100 г [10]. Красная окраска кожуры некоторых сортов яблок также обусловлена накоплением антоцианов, и в настоящее время ведутся работы по селекции яблонь с плодами, у которых антоцианы синтезируются и в мякоти [11]. В то же время известны виды боярышника с плодами с черной окраской, характерной для плодов с усиленным биосинтезом антоцианов. Такие плоды могут быть использованы при приготовлении настоев и чая с антоцианами в качестве основных антиоксидантов (наподобие чая каркаде). Однако информация по типу антоцианов и уровню их накопления в плодах боярышников в научной литературе более чем ограничена. Поэтому задача настоящего исследования - определение содержания и вида антоцианов в плодах некоторых для нас видов боярышника с черными плодами.

\section{Экспериментальная часть}

В работе использовали плоды видов боярышника из коллекции Ботанического сада НИУ БелГУ (I) и Ботанического сада Ботанического института им. В.Л. Комарова РАН (II), собранные в сезоне 2012 г.: C. chlorosarca Maxim. (I, II) и C. pentagyna Waldst. \& Kit. (I).

Экстракцию и очистку антоцианов осуществляли так, как указано в [10]. Видовой состав антоциановых комплексов исследовали методом обращенно-фазовой ВЭЖХ (хроматограф Agilent 1260 с диодноматричным и масс-спектрометрическим детекторами). В качестве элюентов использовали систему ацетонитрил - муравьиная кислота - вода (8: $10: 92)$, при скорости подвижной фазы 1 мл/мин; в работе использовали хроматографическую колонку - 4,06×250 мм Reprosil-Pur C18-AQ 5 мкм с термостатированием при $40{ }^{\circ} \mathrm{C}$. Спектры индивидуальных компонентов записывали в ячейке диодно-матричного детектора. Масс-спектры записывали на квадрупольном масс-спектрометре Agilent 6130 Quadrupole LC/MS в режиме ESI (ионизация распылением в электрическом поле) с позитивным режимом сканирования в диапазоне масс 250-1200. Напряжение на фрагменторе - 200 В. Давление газа-распылителя 2 бар, скорость газа-осушителя 10 л/мин, температура газа-осушителя $350{ }^{\circ} \mathrm{C}$, температура испарителя $250{ }^{\circ} \mathrm{C}$.

Для записи спектров экстрактов использовали спектрофотометр СФ-56.

Антиоксидантную активность экстрактов определяли амперометрическим методом на приборе Цвет Яуза 01-АА. В работе использовали рекомендуемую подвижную фазу - 0,0022 М раствор ортофосфорной кислоты при скорости подачи 1,2 мл/мин и напряжении на электроде 1,3 В. Готовые экстракты перед вводом в систему разбавляли в 50 раз элюентом. В качестве вещества сравнения использовали аскорбиновую кислоту фармакопейную.

\section{Обсужнение результатов}

Хроматограмма экстракта плодов C. chlorosarca представлена на рисунке 1. Времена удерживания всех четырех основных компонентов совпадают с параметрами пиков экстракта плодов аронии черноплодной в тех же хроматографических условиях. Тогда в соответствии с литературными данными [12] можно выполнить предварительное отнесение: пик №1 - цианидин-3-галактозид (Cy-3-Gala), пик №2 - цианидин3-глюкозид (Cy-3-Glu), пик №3 - цианидин-3-арабинозид (Cy-3-Ara) и пик №4 - цианидин-3-ксилозид (Су3-Xyl). Указанное отнесение было подтверждено при исследовании электронных спектров индивидуальных компонентов и их масс-спектров - по отношению масса/заряд молекулярных ионов и ионов агликонов (продуктов фрагментации) (табл. 1).

Таблица 1. Характеристики основных компонентов исследованных в работе экстрактов

\begin{tabular}{|c|c|c|c|c|}
\hline № $^{*}$ & Состав антоциана & $\mathrm{t}_{\mathrm{R}}{ }^{* *}, \mathrm{мин}$ & $\lambda_{\max }{ }^{* *}, \mathrm{HM}$ & $\mathrm{M} / \mathrm{Z}^{* * * *}$ \\
\hline 1 & Цианидин-3-галактозид, Сy-3-Gala & 7,99 & 516, 430 пл, & $287,0,449,1$ \\
\hline 2 & Цианидин-3-глюкозид, Cy-3-Glu & 9,81 & 516, 430 пл, & $287,0,449,1$ \\
\hline 3 & Цианидин-3-арабинозид, Су-3-Ara & 12,22 & 516, 430 пл, & $287,0,419,1$ \\
\hline 4 & Цианидин-3-ксилозид, Су-3-Xуl & 21,48 & 516, 430 пл, & $287,0,419,1$ \\
\hline 5 & Цианидин-3,5-диглюкозид, Cy-3,5-diGlu & 5,49 & 515 & $287,0,611,1$ \\
\hline 6 & Цианидин-3-(2”-глюкозилрутинозид), Су-3 $3^{2 \mathrm{G}} \mathrm{Rut}$ & 8,42 & 519, 430 пл, & $287,0,757,2$ \\
\hline 7 & Цианидин-3-рутинозид, Cy-3-Rut & 12,66 & 517, 430 пл, & $287,0,595,1$ \\
\hline
\end{tabular}

*Номер пиков (рис. 1, 2); ${ }^{* *}$ условия: колонка 250×4 мм Reprosil-Pur C18-AQ, 5 мкм; подвижная фаза: 10 об.\% НСООН, 8 об.\% $\mathrm{CH}_{3} \mathrm{CN}$ в воде, 1 мл/мин (510 нм); спектр записан в ячейке диодно-матричного детектора; ${ }^{* * *}$ записан при напряжении на фрагменторе $150 \mathrm{~B}$. 
Известно, что хроматографический метод определения вещества, основанный на сопоставлении времен удерживания, не относится к абсолютно точным. Но по подавляющему большинству известных литературных данных антоциановый комплекс плодов всех растений трибы яблоневые содержит в качестве основных компонентов именно вещества, приведенные выше [13]. К немногим исключениям относятся результаты трех опубликованных работ [14-16].

В работе [14] сообщалось об обнаружении в яблоках цианидин-7-арабинозида (Су-7-Ara). Это сообщение удивительно тем, что при большом превалировании цианидин-3-галактозида в экстракте обнаружен только Су-7-Ara и не было найдено цианидин-3-галактозид-7-арабинозида. Изменение положения гликозилирования приводит к трансформации электронных спектров антоцианов [17], однако в наших исследованиях электронные спектры всех пиков на хроматограммах, записанные в кювете детектора, были характеристическими для цианидин-3-моногликозидов (рис. 2). В работе [15] утверждалось об обнаружении цианидин-3-(2"-глюкозилрутинозида) (Cy-3 $\left.{ }^{2 \mathrm{G}} \mathrm{Rut}\right)$, хотя хроматограмма, приведенная в работе, весьма напоминает хроматограмму, типичную для антоциановых комплексов плодов растений трибы яблоневые, а декларированного в аннотации доказательства строения компонентов экстракта в статье нет. Отметим, что из плодов растений семейства розоцветные такой антоциан синтезируется в плодах вишни [13]. То, что в нашем случае антоциановые комплексы не содержали Cy-3 ${ }^{2 \mathrm{G}} \mathrm{Rut}$, было однозначно доказано, во-первых, несовпадением времен удерживания компонентов экстракта плодов боярышника с Cy-3 $3^{2 \mathrm{G}} \mathrm{Rut}$ из экстракта плодов вишни сорта Уральская (рис. 3) (в плодах некоторых сортов вишни этот антоциан не синтезируется [18]). И, во-вторых, по нашим данным, увеличение числа углеводных радикалов, связанных друг с другом в положении 3, батохромно смещает максимум абсорбции на 1-1,5 нм (рис. 4) для каждой из добавляемых молекул углеводов, а спектры всех пиков на хроматограмме (рис. 1) соответствуют только цианидин-3монозидам.

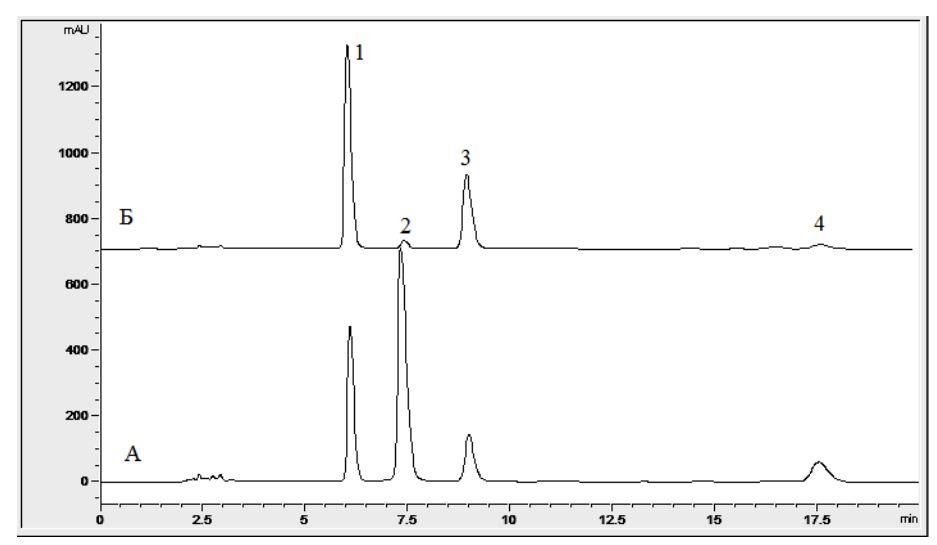

Рис. 1. Разделение антоцианов плодов: А - C. chlorosarca и Б - аронии Мичурина. Антоцианы: 1 - Сy-3-Gala; 2 - Cy-3Glu; 3 - Cy-3-Ara; 4 - Cy-3-Xyl

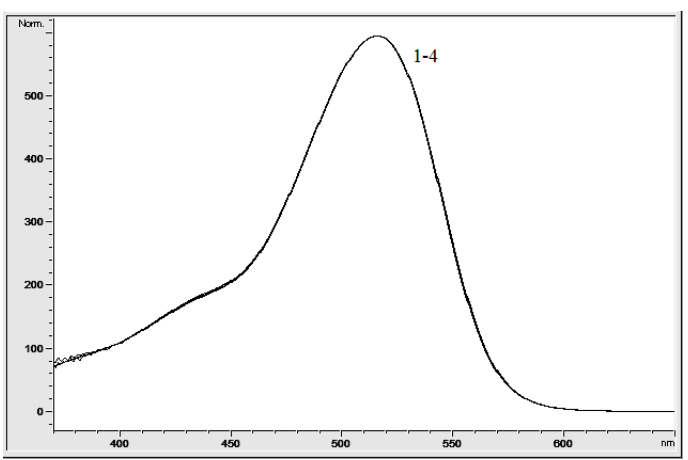

Рис. 2. Электронные спектры

3-могогликозидов цианидина. Номера соединений - номера пиков на рисунке 1

Рис. 3. Разделение антоцианов экстрактов плодов: A - C. pentagyna, Б - лепестков красной розы, В - вишни сорта Уральская: 1 - Сy-3-Gala; 2 - Су3-Glu; 3 - Cy-3-Ara; 4 - Cy-3-Xyl; 5 - Cy-3,5-diGlu; $6-\mathrm{Cy}-3^{2 \mathrm{G}}$ Rut; 7 - Cy-3-Rut

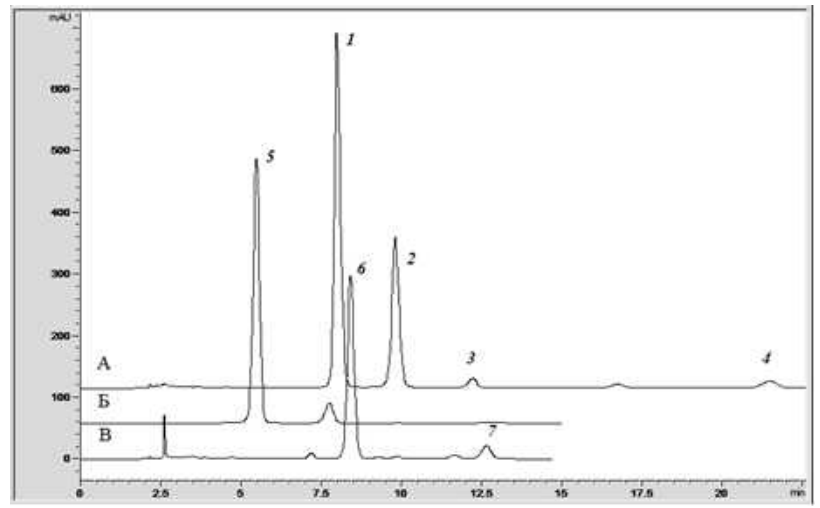


В работе [16] сообщается об обнаружении в плодах четырех видов боярышника - C. pentagyna, - с плодами почти черной окраски, C. kyrtostula, C. caucasica - с плодами темно-красной окраски и $C$. eriantha, - в качестве основного цианидин-3,5-диглюкозида (Cy-3,5-diGlu). Кроме того, сообщается о нахождени цианидин-3-рутинозида и некоторых производных пеларгонидина и пеонидина. Эти результаты очень необычны и должны заинтересовать селекционеров и соответствующих специалистов. Дело в том, что, насколько нам известно, среди растений семейства розоцветные Cy-3,5-diGlu в больших количествах синтезируется лишь в цветках розы, а рутинозиды характерны для плодов косточковых растений. Именно у последних наблюдается также активность метилтрансферазы, приводящая к биосинтезу производных пеонидина, и, наконец, в плодах войлочной вишни основной антоциан - пеларгонидин-3-рутинозид [13, 18]. Однако в нашей работе такие соединения не были обнаружены: Cy-3,5-diGlu заметно отличается от Cy-3-Gala и по хроматографической подвижности (рис. 3), и по характерному изменению спектра при введении гликозидного фрагмента в положение 5 (исчезновение локальной полосы абсорбции при 430 нм) (рис. 4, табл. 1). Производные пеларгониидна и пеонидина должны были бы быть однозначно обнаружены при использовании масс-спектрометрического детектирования, по сигналам ионов агликонов - продуктов фрагментации исходных молекулярных ионов, - но нами были найдены только производные цианидина.

Таким образом, в плодах всех исследованных в настоящей работе видов боярышника обнаружены только производные цианидина, из которых основными являются 3-галактозид, 3-глюкозид и 3-арабинозид и 3-ксилозид. Впрочем, различия между антоциановыми комплексами этих плодов проявляются в относительной доле каждого из компонентов (см. табл. 2).

Уровень накопления антоцианов в плодах исследованных видов боярышника довольно высок - от 0,125-0,200 для плодов боярышника пятипестичного до 0,460-0,620 г на 100 г свежих плодов (в пересчете на цианидин-3-глюкозид хлорид) для плодов боярышника зеленомясого. Но при этом необходимо учитывать, что большая часть плода по объему и массе приходится на семена.

Высокое содержание антоцианов позволяет рассматривать плоды исследованных видов боярышника как местное сырье для приготовления антиоксидантного чая, заменяющего известный напиток каркадэ, основные компоненты которого также антоцианы. Для исследования такой возможности мы высушили плоды боярышника при комнатной температуре вне доступа прямого солнечного света. Затем одинаковые навески чая каркадэ и размолотого в бытовой кофемолке порошка высушенных плодов боярышника зеленомясого (вместе с семенами) залили кипятком и выдержали в течение 8 мин. Оба полученные настоя каркадэ (К) и боярышника (Б) имели красный характерный для антоцианов цвет, интенсивность которого в случае каркаде оказалась выше. Но при этом настои существенно различались по рН: К - 2,66; Б - 4,30. Учитывая известное свойство антоцианов - практически полный переход окрашенной флавилиевой формы в бесцветную полуацетальную форму при $\mathrm{pH}=4,5,-$ можно считать, что окраска настоя Б в данном случае обусловлена в основном полимерными антоцианами. И действительно, спектр экстракта при рН = 4,3 заметно отличается от спектра при $\mathrm{pH}=1$ (рис. 5) уширением полосы абсорбции и с небольшим смещением в длинноволновую область.

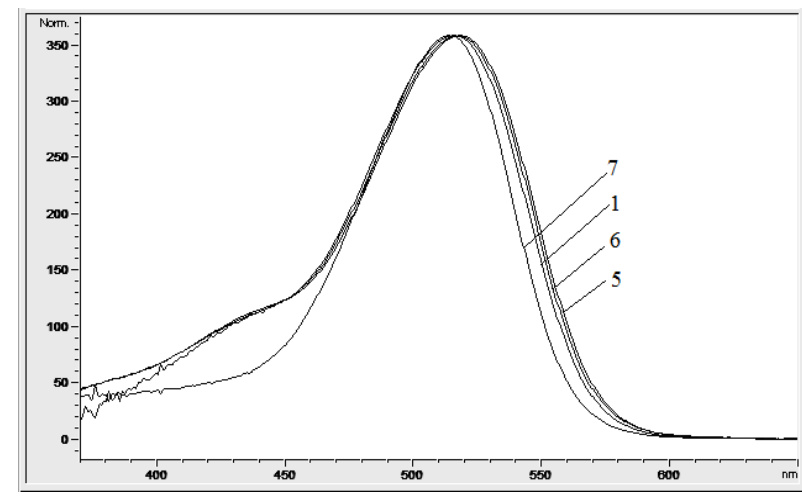

Рис. 4. Электронные спектры производных цианидина. Антоцианы: 1 - Cy-3-Gala; 5 - Cy- $3^{2 \mathrm{G}}$ Rut, 6 - Cy-3Rut; 7 - Cy-3,5-diGlu

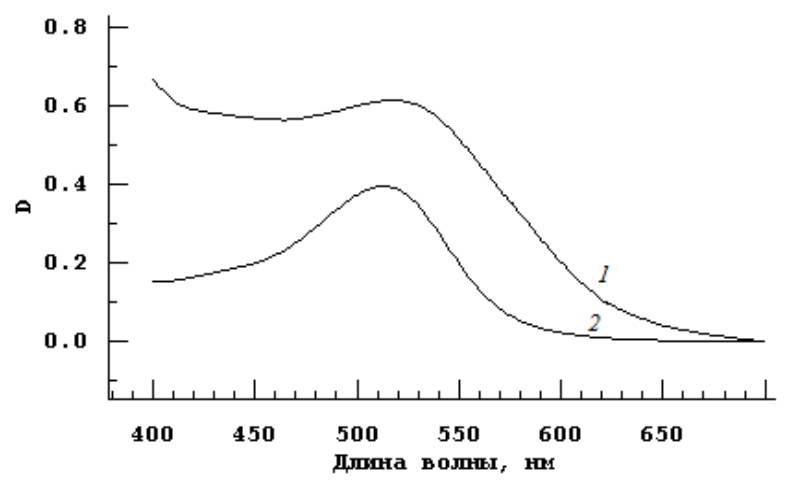

Рис. 5. Спектры экстрактов плодов C. Chlorosarca: 1 - водный экстракт; 2 - тот же экстракт, но разбавленный в $0,1 \mathrm{M}$ водном растворе $\mathrm{HCl}$ 
Таблица 2. Видовой состав антоцианов экстрактов плодов видов рода боярышник

\begin{tabular}{c|l|c|c|c|c}
\hline \multirow{2}{*}{$№$} & \multirow{2}{*}{ Вид Crataegus } & \multicolumn{3}{|c}{ Доля по площадям пиков, моль \% ( $\pm 0.5 \%)$} \\
\cline { 3 - 6 } & & Cy-3-Gala & Cy-3-Glu & Cy-3-Ara & Cy-3-Xyl \\
\hline 1 & C. Chlorosarca & 27,9 & 51,6 & 9,5 & 8,9 \\
2 & C. Pentagyna & 57,5 & 33,1 & 2,4 & 1,1 \\
\hline
\end{tabular}

Из представленных результатов следует, что, во-первых, при приготовлении напитка из высушенных плодов боярышника зеленомясого желательно добавить кислоту (например, лимонную) для перевода антоцианов во флавилиевую окраску. Во-вторых, очевидно, что при сушке плодов боярышника зеленомясого происходит частичное разрушение мономерных антоцианов с образованием полимерных соединений. При этом для плодов пятипестичного боярышника высушивание не привело к подобным изменениям спектры экстрактов (при рН = 1) оказались неотличимыми от спектров мономерных антоцианов (рис. 6).

Наконец, в работе была сопоставлена антиоксидантная активность экстрактов К и Б амперометрическим методом. В пересчете на аскорбиновую кислоту (АК) антиоксидантная активность настоя К составила 163 мг, а настоя Б несколько меньше - 127 мг/л. Но следует учитывать, что в использованном материале на основе боярышника содержались балластные части - семена. При их удалении перед сушкой растительного сырья в таком случае можно рассчитывать на получение материала с большей антиоксидантной активностью и с более высоким уровнем содержания антоцианов по сравнению с высушеными бутонами гибискуса суданского (каркаде).

Рис. 6. Спектры экстрактов высушенных плодов трех видов боярышника. $1-$ C. pentagyna, $2-$ C. chlorosarca, $\mathrm{pH}=1$

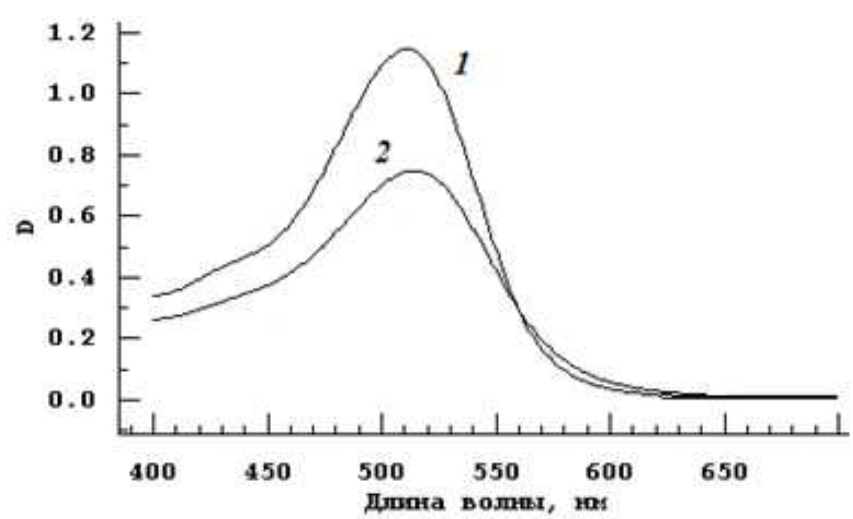

\section{Выводы}

Плоды трех видов черноплодных боярышников оказались богатыми источниками антоцианов с традиционным для растений подсемейства яблоневые видовым составом этих соединений. Плоды $C$. chlorosarca являются ценным сырьем для приготовления напитков с высокой антиоксидантной активностью. Очевидно, что этот вид флоры российского Дальнего Востока (Камчатка, острова Сахалин и Кунашир) и Японии, боярышник зеленомясый, нуждается в более широком введении в культуру.

\section{Список литературы}

1. Mónica Giusti M., Wrolstad R.E. Characterization and Measurement of Anthocyanins by UV-Visible Spectroscopy // Current Protocols in Food Analytical Chemistry. John Wiley \& Sons, Inc. 2001. F1.2.1-F1.2.13.

2. Einbond L.S., Reynertson K.A., Luo X.-D., Basile M.J., Kennelly E.J. Anthocyanin antioxidants from edible fruits // Food Chem. 2004. Vol. 84. Pp. 23-28.

3. Ghosh D., Konishi T. Anthocyanins and anthocyanin-rich extracts: role in diabetes and eye function // Asia Pac. J. Clin. Nutr. 2007. Vol. 16. Pp. 200-208.

4. Deroles S. Anthocyanin Biosynthesis in Plant Cell Cultures: A Potential Source of Natural Colourants / In «Anthocyanins. Biosynthesis, Functions, and Applications» Ed. Gould K., Davies K., Winefield C. 2009. Springer Science+Business Media LLC. Pp. 107-168.

5. Kähkönen M.P., Heinonen M. Antioxidant Activity of Anthocyanins and Their Aglycons // J. Agric. Food Chem. 2003. Vol. 51. Pp. 628-633.

6. Камелин Р.В. Сем. 90. Rosaceae Adans. - Розовые // Флора Восточной Европы. СПб., 2001. Т. Х. С. $306-313$.

7. Цвелев Н.Н. Род 38. Боярышник - Crataegus L. // Флора Восточной Европы. СПб., 2001. T. Х. C. 557-586.

8. Чулков А.Н., Дейнека В.И., Сорокопудов В.Н., Дейнека Л.А., Степанова Ф.И. Антоцианы плодов шести видов Amelanchier sp. // Научн. Ведом. БелГУ. Сер. Ест. науки. 2011. №9, Вып.15/2. С. 208-214.

9. Nocker S. van, Berry G., Najdowski J., Michelutti R., Luffman M., Forsline P., Alsmairat N., Beaudry R., Nair M.G., Ordidge M. Genetic diversity of red-fleshed apples (Malus) // Euphytica. 2012. Vol. 185. Pp. 281-293. 
10. Kulling S.E., Rawel H.M. Chokeberry (Aronia melanocarpa) - A Review on the Characteristic Components and Potential Health Effects // Planta Med. 2008. Vol. 74. Pp. 1625-1634.

11. Дейнека В.И., Григорьев А.М., Дейнека Л.А., Ермаков А.М., Сиротин А.А., Староверов В.М. Анализ компонентного состава антоцианов плодов и жирных кислот масел семян некоторых видов семейства Rosaceae методом высокоэффективной жидкостной хроматографии // Растительные ресурсы. 2005. Вып. 1. С. 91-98.

12. Sun B.H., Francis F.J. Apple Anthocyanins: Identification of cyanidin-7-arabinoside // J. Food Sci. 1967. Vol. 32. Pp. 647-649.

13. Mulabagal V., Van Nocker S., Dewitt D.L., Nair M.G. Cultivars of apple fruits that are not marketed with potential for anthocyanin production // J. Agric. Food Chem. 2007. Vol. 55. Pp. 8165-8169.

14. Аббасова Т.Ю., Новрузов Э.Н., Мамедов Э.И. Антоцианы плодов некоторых видов Crataegus L. // Химия растительного сырья. 2012. №3. С. 177-180.

15. Harborne J.B. Spectral Methods of Characterizing Anthocyanins // Biochem. J. 1958. Vol. 70. Pp. 22-28.

16. Дейнека Л.А., Чулков А.Н., Дейнека В.И., Сорокопудов В.Н., Шевченко С.М. Антоцианы плодов вишни и родственных растений // Научные ведомости БелГУ Сер. Ест. науки. 2011. №9, Вып. 15/1. С. 364-370.

Поступило в редакичию 26 февраля 2013 г.

Deineka V.I. ${ }^{\text {I* }}$, Makarevitch S.L. ${ }^{1}$, Deineka L.A. ${ }^{1}$, Firsov G.A. ${ }^{2}$, Sorokopudov V.N. ${ }^{1}$, Tret'jakov M.Yu. ${ }^{1}$, Bakshutov S.A. ${ }^{l}$ ANTHOCYANINS OF SOME HAWTHORN SPECIES (CRATAEGUS L., ROSACEAE) FRUITS

${ }^{l}$ National Research University Belgorod State University, Pobeda str. 85, Belgorod, 308015 (Russia),

e-mail:deineka@bsu.edu.ru

${ }^{2}$ Komarov Botanical Institute RAS, Professor Popov str, 2, Saint Petersburg, 197376, (Russia),

e-mail: gennady_firsov@mail.ru

Anthocyanins of two hawthorn species fruits: C. chlorosarca Maxim. and C. pentagyna Waldst. et Kit., were investigated by HPLC-DAD-ESI-MS method. Cyanidin-3-galactoside, cyanidine-3-glucoside, cyanidine-3-arabinoside and cyanidine-3xiloside were found. Overall anthocyanins accumulation was the highest in the case of C. chlorosarca fruits: $0.460 \div 0.620 \mathrm{~g}$ per $100 \mathrm{~g}$ of fresh fruits as cyanidine-3-glucoside chloride equivalent. It has been found that according to anthocyanins accumulation as well as to the antioxidant activity $\mathrm{C}$. chlorosarca fruits are rather comparable to dried hibiscus subdariffa calyces and may be used for another tea preparation at some acidification.

Keywords: anthocyanins, Crataegus, fruits, antioxidant activity.

\section{References}

1. Mónica Giusti M., Wrolstad R.E. Current Protocols in Food Analytical Chemistry, John Wiley \& Sons, Inc. 2001. F1.2.1-F1.2.13.

2. Einbond L.S., Reynertson K.A., Luo X.-D., Basile M.J., Kennelly E.J. Food Chem., 2004, vol. 84, pp. $23-28$.

3. Ghosh D., Konishi T. Asia Pac. J. Clin. Nutr., 2007, vol. 16, pp. 200-208.

4. Deroles S. Anthocyanins. Biosynthesis, Functions, and Applications. Ed. Gould K., Davies K., Winefield C. 2009. Springer Science+Business Media LLC. Pp. 107-168.

5. Kähkönen M.P., Heinonen M. J. Agric. Food Chem., 2003, vol. 51, pp. 628-633.

6. Kamelin R.V. Flora Vostochnoi Evropy. [Flora of Eastern Europe.]. St. Petersburg, 2001, vol. X, pp. 306-313. (in Russ.).

7. Tsvelev N.N. Flora Vostochnoi Evropy. [Flora of Eastern Europe.]. St. Petersburg, 2001, vol. X, pp. 557-586. (in Russ.).

8. Chulkov A.N., Deineka V.I., Sorokopudov V.N., Deineka L.A., Stepanova F.I. Nauchnye vedomosti BelGU. Ser. Est. nauki., 2011, no. 9, part 15/2. pp. 208-214. (in Russ.).

9. van Nocker S., Berry G., Najdowski J., Michelutti R., Luffman M., Forsline P., Alsmairat N., Beaudry R., Nair M.G., Ordidge M. Euphytica, 2012, vol. 185, pp. 281-293.

10. Kulling S.E., Rawel H.M. Planta Med., 2008, vol. 74, pp. 1625-1634.

11. Deineka V.I., Grigor'ev A.M., Deineka L.A., Ermakov A.M., Sirotin A.A., Staroverov V.M. Rastitel'nye resursy, 2005, no. 1, pp. 91-98. (in Russ.).

12. Sun B.H., Francis F.J. J. Food Sci., 1967, vol. 32, pp. 647-649.

13. Mulabagal V., Van Nocker S., Dewitt D.L., Nair M.G. J. Agric. Food Chem., 2007, vol. 55, pp. 8165-8169.

14. Abbasova T.Iu., Novruzov E.N., Mamedov E.I. Khimiia rastitel'nogo syr'ia, 2012, no. 3, pp. 177-180. (in Russ.).

15. Harborne J.B. Biochem. J., 1958, vol. 70, pp. 22-28.

16. Deineka L.A., Chulkov A.N., Deineka V.I., Sorokopudov V.N., Shevchenko C.M. Nauchnye vedomosti BelGU Ser. Est. Nauki, 2011, no. 9, part 15/1, pp. 364-370.

\footnotetext{
* Corresponding author.
} 